\title{
Late-term effects of hypofractionated chest wall and regional nodal radiotherapy with two-dimensional technique in patients with breast cancer
}

\author{
Budhi Singh Yadav , Anshuma Bansal ${ }^{2}$, Philip George Kuttikat', Deepak Das', Ankita Gupta ${ }^{1}$, Divya Dahiya ${ }^{3}$ \\ ${ }^{1}$ Department of Radiation Oncology, Regional Cancer Centre, Postgraduate Institute of Medical Education \& Research, Chandigarh, India \\ ${ }^{2}$ Department of Radiation Oncology, Rajindra Hospital, Patiala, Punjab, India \\ ${ }^{3}$ Department of General Surgery, Postgraduate Institute of Medical Education \& Research, Chandigarh, India
}

Received: March 18, 2020

Revised: April 24, 2020

Accepted: May 4, 2020

\section{Correspondence:}

Budhi Singh Yadav

Department of Radiation Oncology,

Postgraduate Institute of Medical

Education \& Research, Sector-12,

Chandigarh, India.

Tel: +919815981176

E-mail:drbudhi@gmail.com

ORCID:

https://orcid.org/0000-0001-6185-4139
Purpose: Hypofractionated radiotherapy (RT) is becoming a new standard in postoperative treatment of patients with early stage breast cancer after breast conservation surgery. However, data on hypofractionation in patients with advanced stage disease who undergo mastectomy followed by local and regional nodal irradiation (RNI) is lacking. In this retrospective study, we report late-term effects of 3 weeks post-mastectomy hypofractionated local and RNI with two-dimensional (2D) technique in patients with stage II and III breast cancer.

Methods: Between January 1990 and December 2007, 1,770 women with breast cancer who were given radical treatment with mastectomy, systemic therapy and RT at least 10 years ago were included. RT dose was $35 \mathrm{~Gy} / 15$ fractions/3 weeks to chest wall by two tangential fields and $40 \mathrm{~Gy}$ in same fractions to supraclavicular fossa (SCF) and internal mammary nodes (IMNs). SCF and IMNs dose was prescribed at $d_{\max }$ and $3 \mathrm{~cm}$ depth, respectively. Chemotherapy and hormonal therapy was given in 64\% and 74\% patients, respectively. Late-term toxicities were assessed with the Radiation Therapy Oncology Group (RTOG) scores and LENT-SOMA scales (the Late Effects Normal Tissue Task Force-Subjective, Objective, Management, Analytic scales).

Results: Mean age was 48 years (range, 19 to 75 years). Median follow-up was 12 years (range, 10 to 27 years). Moderate/marked arm/shoulder pain was reported by 254 (14.3\%) patients. Moderate/ marked shoulder stiffness was reported by $219(12.3 \%)$ patients. Moderate/marked arm edema was seen in $131(7.4 \%)$ patients. Brachial plexopathy was not seen in any patient. Rib fractures were noted in $6(0.3 \%)$ patients. Late cardiac and lung toxicity was seen in $29(1.6 \%)$ and $23(1.3 \%)$ patients, respectively. Second malignancy developed in 105 (5.9\%) patients.

Conclusion: RNI with $40 \mathrm{~Gy} / 15$ fractions/3 weeks hypofractionation with 2D technique seems safe and comparable to historical data of conventional fractionation (ClinicalTrial.gov Registration No. NCT04175821).

Keywords: Breast cancer, Hypofractionation, Radiotherapy, Long-term effects, Postmastectomy

\section{Introduction}

Survival of breast cancer patients has improved with multimodality treatment [1]. Hypofractionated radiotherapy (RT) is rapidly emerging as one of the options for breast cancer patients after breast-conserving surgery (BCS) [2-4] but data on postmastectomy radiation therapy (PMRT) with hypofractionation is lacking. There is always a concern for late effects of RT especially with re-

Copyright@ 2020 The Korean Society for Radiation Oncology

This is an Open Access article distributed under the terms of the Creative Commons Attribution Non-Commercial License (http://creativecommons.org/licenses/by-nc/4.0/) which permits unrestricted non-commercial use, distribution, and reproduction in any medium, provided the original work is properly cited. 
gional nodal irradiation (RNI). The potential survival benefit of locoregional radiation needs to be balanced with late-term effects [5]. Therefore, reporting late-term effects of radiation in these patients is of utmost importance, especially with hypofractionation. Very few patients were given PMRT and RNI in the START trials, so it may not be possible to establish the safety of shorter fractionation RNI from these studies [2-4]. Recently, a randomised study was done by Wang et al. [6] in high risk patients after mastectomy. At 5 years, they reported similar clinical outcomes and late toxicities with conventional and hypofractionation [6]. There are a few studies from Canada and the United States with similar dose fractionations in PMRT setting with small number of patients but without RNI $[7,8]$. So, there is a worldwide need of data on PMRT and RNI to establish its long-term safety in patients with breast cancer. Because of this, many radiation oncology societies are hesitant to recommend hypofractionated RNI. It is also an area for potential research in breast cancer radiotherapy. We have published our clinical outcomes with 3 weeks of postoperative local and RNI with hypofractionation in breast cancer in the past [9-13]. In this retrospective study, we report late-term effects of PMRT and RNI with this schedule in patients with stage II and III breast cancer treated with two-dimensional (2D) technique from a regional cancer centre in XXXX which is practicing hypofractionation in breast cancer since 1976.

\section{Materials and Methods}

Between January 1990 and December 2007, women with breast cancer who were given radical treatment with mastectomy, systemic therapy and RT at least 10 years ago were included. Eligible patients were followed in the radiation oncology department breast clinic. The study was approved by the departmental committee and registered in ClinicalTrials.gov with No. NCT04175821. Clinical, pathological and treatment characteristics were taken from the patient's file. Inclusion criteria were female patients age $\geq 18$ years of age, with invasive carcinoma of the breast, postmastectomy, and stage II or III disease treated with locoregional RT. Exclusion criteria were: BCS, stage I or IV disease, past history of malignancy except (1) basal cell skin cancer or cervical intraepithelial neoplasia (CIN) cervix uteri or (2) non-breast malignancy if treated with curative intent and at least 5 years disease-free or contralateral breast cancer, including ductal carcinoma in situ (DCIS), irrespective of date of diagnosis. Patients with bilateral breast cancer were also excluded.

All patients were planned in supine position on a breast board with ipsilateral arm abducted to $90^{\circ}$ using 2D fluoroscopic conventional simulator. Chest wall was treated by two tangential fields.
Field marking for breast/chest wall included midline medially, midaxillary fold laterally, 2nd intercostal space cranially and $1 \mathrm{~cm}$ below the opposite inframammary fold caudally. Central lung distance (CLD) was noted for each patient (Fig. 1A). Supraclavicular fossa (SCF) was treated by a single incident field. Its caudal border was the cranial border of the chest wall field, cranially thyroid notch, medially along the medial border of the sternocleidomastoid muscle
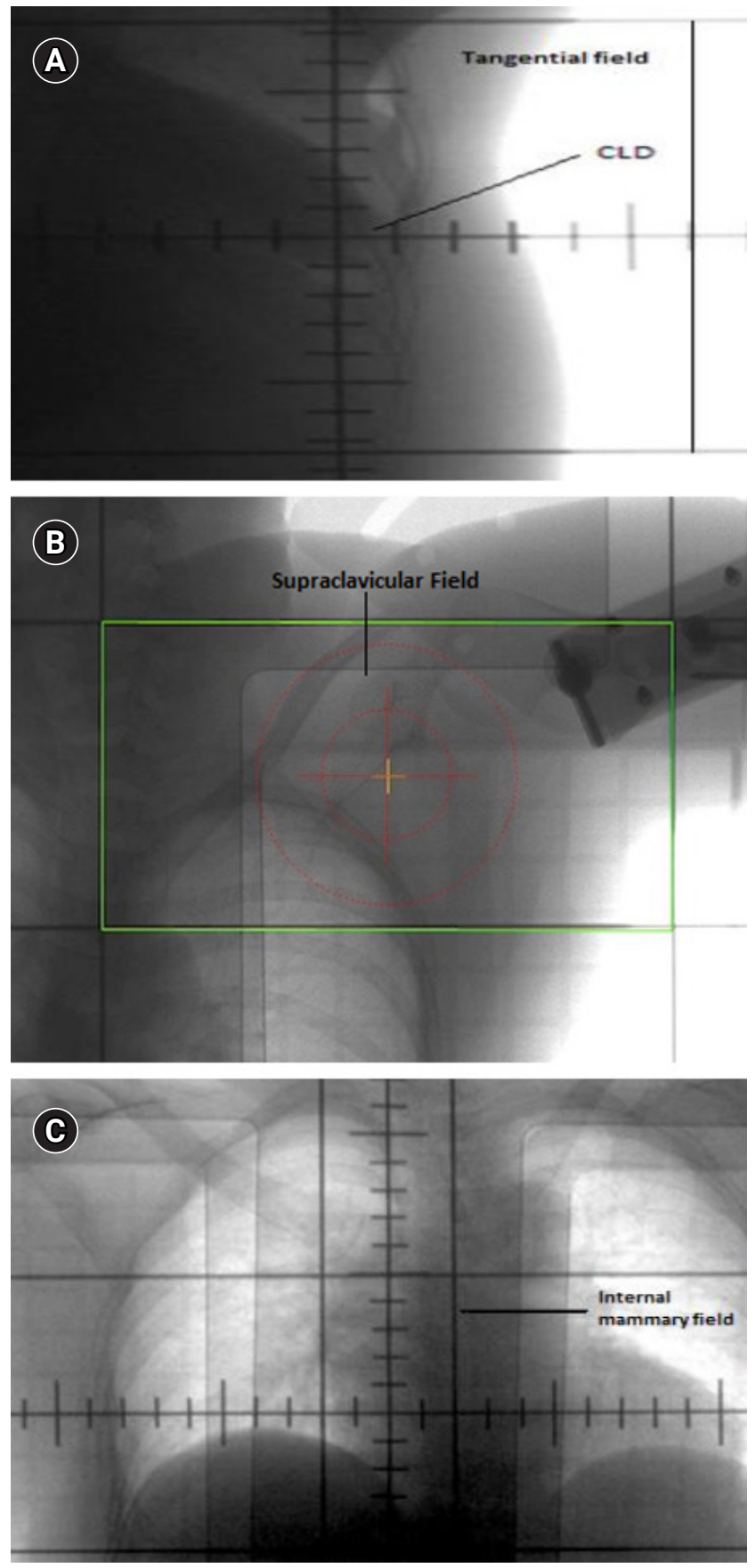

Fig. 1. (A) Tangetial field portal with central lung distance (CLD). (B) Supraclavicular field portal. (C) Internal mammary field portal. 
and laterally insertion of deltoid (Fig. 1B). No posterior axillary field was used. The head of the humerus was shielded in patients with adequate axillary dissection with $<25 \%$ nodes involved.

RT dose delivered was $35 \mathrm{~Gy} / 15$ fractions ( $\mathrm{fx}) / 3$ weeks to the chest wall. Dose was prescribed at mid-separation. Bolus was used in all patients on alternate days that is for $50 \%$ of treatment. In patients with positive margins bolus was used daily and a scar boost of 10-15 Gy/4-5 fx was given. None of the patients had breast reconstruction. The breast cone was used in patients treated on cobalt, which had a shielding block to reduce penumbra and lung dose.

Internal mammary nodes (IMNs) were irradiated with a separate $12 \times 5 \mathrm{~cm}^{2}$ single field (Fig. 1C). The first five intercostal spaces were included in the IMN target volume. The medial border of the IMN field was midline; lateral border $5 \mathrm{~cm}$ lateral to the midline; the superior border abuts the inferior border of the supraclavicular field; and the inferior border was above the xiphoid [9]. The dose delivered was $40 \mathrm{~Gy} / 15 \mathrm{fx} / 3$ weeks prescribed at $3 \mathrm{~cm}$ depth. SCF was treated with a single field and dose was prescribed at $d_{\max }$. Patients were treated on linear accelerator (LINAC) or cobalt-60 machine.

Biologically effective dose (BED) of $35 \mathrm{~Gy} / 15 \mathrm{fx} / 3$ weeks is 62.2 $\mathrm{Gy}_{3}$ in terms of $2 \mathrm{~Gy}$ per fraction for late effects, $43.17 \mathrm{~Gy}_{10}$ for tumour control, 45 Gy for erythema and 42.3 Gy for desquamation in case of chest wall radiotherapy. The BED for RNI with this schedule is $75.47 \mathrm{~Gy}_{3}, 50.64 \mathrm{~Gy}_{10}, 52.5 \mathrm{~Gy}$ and $49 \mathrm{~Gy}$ for late effects, tumour control, erythema, and desquamation, respectively.

Dosimetric study was also done in 50 patients with left side breast cancer. Patients were planned on a 2D simulator on breast board. Field borders were set as described above and CLD was calculated. Field borders were marked. After that patients were taken to computed tomography (CT)-simulator for 3D treatment planning. The patients were positioned supine on same breast board in same position with same parameters as were on 2D simulator. Lead wires were placed on the field borders of chest wall and $100 \mathrm{~mL}$ of intravenous (IV) contrast was given. CT axial cuts were taken from the level of larynx to upper abdomen, including both the lungs with a scan thickness and index of $3 \mathrm{~mm}$. Then, the CT images were transferred to the treatment planning system. The chest wall, heart, bilateral lungs, left anterior descending (LAD) artery, and opposite breast were contoured. A CT-based 3D planning was generated form the 2D marked target area for treating chest and locoregional lymph nodes (Fig. 2A). Plans were made using standard tangent fields. Heart, bilateral lungs, LAD artery, and opposite breast dose-volume histogram (Fig. 2B) were generated to see how much dose was received by organs-at-risk. From these, estimate of mean doses to heart, $L A D$, proximal $L A D$, distal $L A D$, bilateral lungs and opposite breast, $V_{5}$ of right lung, $V_{5}, V_{10}$, and $V_{20}$ of left lung and $V_{2}$ opposite breast were calculated. Treatment was done with 2D technique.

Patients were followed regularly 3 monthly during first year, 4 monthly in the second and third year, 6 monthly till 5 years, yearly till 10 years and 2 yearly thereafter. Necessary investigations were done to pick up the recurrence/metastasis and late toxicities depending on the symptoms of the patients.

Patients were examined by the radiation oncologists with special focus on shoulder function, lymphedema, arm pain, and sensory symptoms. Lymphedema was graded by measuring arm circumference $10 \mathrm{~cm}$ above and below the medial epicondyle of humerus. For lymphedema and shoulder function, the treated side was compared with the untreated opposite side as a reference. Lymphedema was classified as none, mild, moderate and marked if there was no difference, $0.5-2 \mathrm{~cm}, 2.1-3 \mathrm{~cm}$, and $>3 \mathrm{~cm}$ difference, respectively in the circumference of the affected and normal arm. If the patient had symptoms of pain in the arm, paresthesia, numbness, weakness, or other sensory symptoms then injury to the brachial plexus was suspected and reported as brachial plexopathy. Late lung toxicity was defined grade 1 as asymptomatic or mild symptoms of dry cough, slight radiographic changes; grade 2 as moderate symptomatic fibrosis or pneumonitis (severe cough), low grade fever, patchy radiographic changes; grade 3 as severe symptomatic fibrosis or pneumonitis, dense radiographic changes; and grade 4 as severe respiratory insufficiencies, oxygen required of assisted ventilation. Late cardiac toxicity was defined grade 1 as minimal enlargement of cardiac silhouette (ECS); grade 2 as ECS without pulmonary congestion; grade 3 as ECS pulmonary congestion; and grade 4 as ECS with frank pulmonary oedema. All late effects assessment scores were dichotomised as none/mild versus moderate/ marked effects. Coronary events were defined as myocardial infarction, ischaemic heart failure, unstable angina or sudden death. A four point scale (none, a little, quite a bit, very much) was used to assess all late effects according to the LENT-SOMA scale. All late effects assessment scores were dichotomised as none/mild versus moderate/marked effects. Second malignancy was defined as cancer developing after 6 months of treatment of breast cancer except basal cell carcinoma of the skin and carcinoma in situ of cervix.

\section{Results}

\section{Patient and tumour characteristics}

A total 1,770 patients met the eligibility criteria. Mean age was 48 years (range, 19 to 75 years). The median follow-up was 12 years (range, 10 to 27 years). Characteristics of patients are as shown in Table 1. 
A

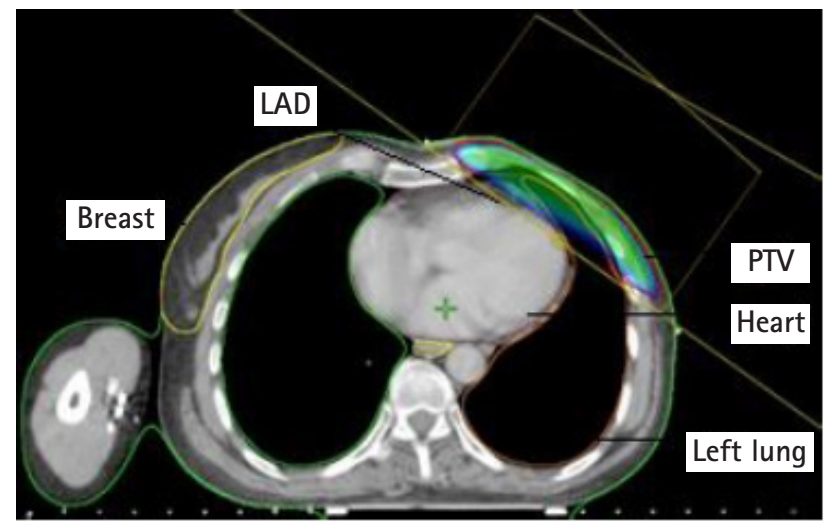

B

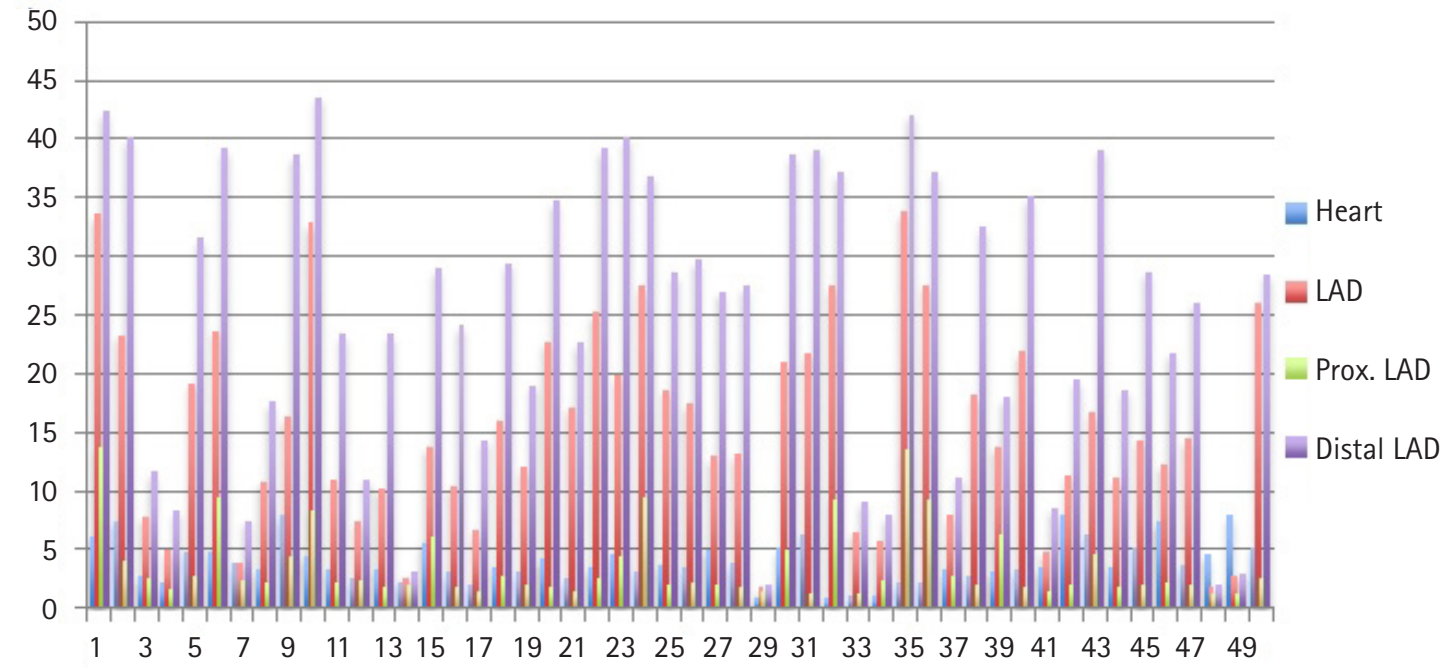

(C)

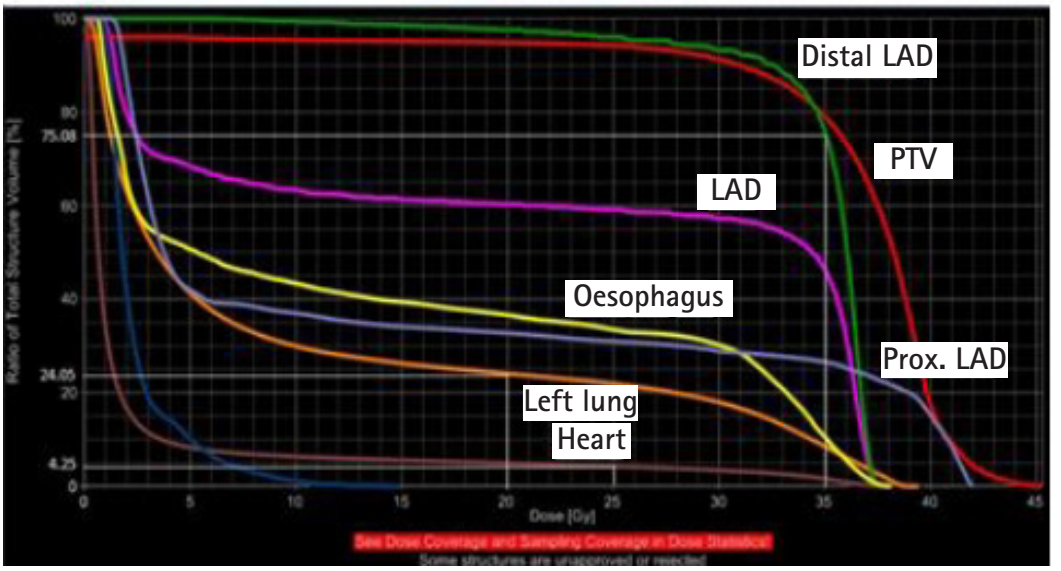

Fig. 2. (A) Organs-at-risk (OARs) and planning target volume (PTV) covered by 95\% isodose. (B) Mean doses to OARs (dose along y-axis and patients along $x$-axis). (C) Dose volume histogram showing dose to PTV and OARs. LAD, left anterior descending; Prox, proximal.

\section{Treatments received}

Surgery was modified radical mastectomy and total mastectomy with axillary clearance in 762 (43\%) and 1,008 (57\%) patients, respectively. Median number of axillary nodes dissected were 10. Chemotherapy was given to $1,136(64 \%)$ patients. Chemotherapy regimens included CMF (cyclophosphamide, methotrexate and 5-fluorouracil), anthracycline, and anthracyclines and taxane-based chemotherapy in 443 (39\%), 455 (40\%), and 240 (21\%) patients, respectively. Hormonal therapy was given to 1,310 (74\%) patients.

Right and left chest wall was irradiated in 973 (55\%) and 797 (45\%) patients, respectively. RNI was delivered in 1,689 (95\%) pa- 
Table 1. Patient characteristics $(n=1,770)$

\begin{tabular}{|c|c|}
\hline Characteristic & Value \\
\hline \multicolumn{2}{|l|}{ Age (yr) } \\
\hline$\leq 40$ & $491(28)$ \\
\hline$>40$ & $1,279(72)$ \\
\hline \multicolumn{2}{|l|}{ Laterality } \\
\hline Right & $973(55)$ \\
\hline Left & $797(45)$ \\
\hline \multicolumn{2}{|l|}{ Menopausal status } \\
\hline Pre-menopausal & $828(47)$ \\
\hline Post-menopausal & $942(53)$ \\
\hline \multicolumn{2}{|l|}{ Tumor stage } \\
\hline $\mathrm{T} 1$ & $906(51)$ \\
\hline $\mathrm{T} 2$ & 659 (37) \\
\hline T3 & $34(2)$ \\
\hline T4 & $171(10)$ \\
\hline \multicolumn{2}{|l|}{ Histology } \\
\hline IDC & $1,628(92)$ \\
\hline Non-IDC & $142(8)$ \\
\hline \multicolumn{2}{|l|}{ Grade } \\
\hline 1 & $318(18)$ \\
\hline 2 & $1,134(64)$ \\
\hline 3 & 318 (18) \\
\hline \multicolumn{2}{|l|}{ N stage (pathological) } \\
\hline pNo & 654 (37) \\
\hline $\mathrm{pN} 1$ & $593(34)$ \\
\hline pN2 & $383(22)$ \\
\hline pN3 & $140(8)$ \\
\hline \multicolumn{2}{|l|}{ Surgical margins } \\
\hline Negative & $1,562(88)$ \\
\hline Positive & $208(12)$ \\
\hline \multicolumn{2}{|c|}{ Estrogen receptor status } \\
\hline Positive & $859(49)$ \\
\hline Negative & $530(30)$ \\
\hline Unknown & $381(21)$ \\
\hline \multicolumn{2}{|c|}{ Progesterone receptor status } \\
\hline Positive & $729(41)$ \\
\hline Negative & $632(36)$ \\
\hline Unknown & 409 (23) \\
\hline \multicolumn{2}{|l|}{ Chemotherapy } \\
\hline Yes & $1,136(64)$ \\
\hline No & $634(36)$ \\
\hline \multicolumn{2}{|l|}{ Hormonal therapy } \\
\hline Yes & $1,310(74)$ \\
\hline No & $460(26)$ \\
\hline
\end{tabular}

Values are presented as number of patients (\%).

IDC, invasive ductal carcinoma.

tients. Internal mammary nodal irradiation (IMNI) was delivered in 154 (9\%) patients. Average CLD was $2 \mathrm{~cm}$ (range, 1 to $3 \mathrm{~cm}$ ). In 50 patients with left breast cancer in whom dosimetry was done their dosimetric data is shown in Fig. 2B. Mean doses to the heart, LAD, proximal LAD, and distal LAD were 3.364 Gy, $16.06 \mathrm{~Gy}, 2.7 \mathrm{~Gy}$, and $27.5 \mathrm{~Gy}$, respectively. Left lung mean dose, $\mathrm{V}_{5}, \mathrm{~V}_{10}$, and $\mathrm{V}_{20}$ were 5.96 Gy, 16\%, 14\%, and 12.4\%, respectively. Mean dose to the right lung and the opposite breast was $0.29 \mathrm{~Gy}$ and $0.54 \mathrm{~Gy}$, respectively. DVH is shown in Fig. 2C. $V_{25}$ for heart was $4.25 \%$ where as $V_{35}$ for distal LAD was $75 \%$ as compared to $26 \%$ for distal LAD. V30 for the oesophagus was $30 \%$.

\section{Toxicities}

Late toxicity rates are summarized in Table 2. Moderate/marked arm/shoulder pain was reported by 254 patients (14.3\%; 95\% confidence interval [Cl], 12.7-16.1). Moderate/marked shoulder stiffness reported by 219 patients (12.3\%; 95\% Cl, 10.9-14.0). Arm oedema developed in 131 patients $(7.4 \% ; 95 \% \mathrm{Cl}, 6.2-8.7)$. Lymphedema rate significantly increased with the number of axillary lymph nodes dissected (Table 3). It was 4.9\%, 9\%, and $12.6 \%$ in patients with $\leq 10,11-20$, and $>20$ axillary lymph nodes dissected, respectively.

Brachial plexopathy was not seen in any of the patients. Arm/ shoulder pain and stiffness decreased at 10 and 15 years. Arm edema rate was similar at 5, 10, and 15 years. Late grade III cardiac toxicity was seen in 29 patients $(1.6 \% ; 95 \% \mathrm{Cl}, 1.1-2.3)$. Coronary events were reported in 7 patients $(0.3 \%$; $95 \% \mathrm{Cl}, 0.1-0.7)$. Coronary bypass surgery and stent placement was done in 3 patients each. Pacemaker was inserted in one patient. Four of these had received IMNI, 3 for left and 1 for right breast cancer, respectively. Late grade III lung toxicity (on the treated side) was seen in 23 patients (1.3\%; 95\% Cl, 0.8-1.9) (Table 2). Lung and cardiac toxicities were constant at 10 and 15 years. Rib fractures were noted in 6 patients $(0.3 \% ; 95 \% \mathrm{Cl}, 0.1-0.7)$ on the treated side. There was no association between the dosimetric factors and lung and heart toxicities in these patients.

Second malignancy developed in 105 patients (5.9\%; 95\% Cl, 4.9-7.1). Most common site of second malignancy was opposite breast in 61 (3.3\%) patients. Non-breast second malignancy developed in 44 (2.3\%) patients. Most common non-breast second malignancy was gynaecological 25 (1.3\%); 6, 8, and 11 in cervix, endometrium, and ovary, respectively. Gastrointestinal tract $9(0.5 \%)$; 4 in oesophagus (radiation related), 3 colon, 1 stomach, 1 gall bladder, and 1 rectum. Haematological, thyroid (radiation related), and renal $2(0.1 \%)$ each. Others were carcinoma of lung (on the untreated side), vallecula and liposarcoma (on the treated side) one each. Rate of second malignancies increased over 5, 10, and 15 years (Table 2). 


\section{Discussion and Conclusion}

In the present study, late-term toxicities were modest following 3 weeks postmastectomy hypofractionated locoregional RT. Our findings suggest that RNI with hypofractionation may be as safe as conventional fractionation.

This is a large study on postmastectomy hypofractionated regional RT with long-term follow-up reporting late-term effects in patients with breast cancer. Our results indicate that arm and shoulder functions improved over the years (Table 2). The START trials also reported late effects after hypofractionated PMRT and RNI [2-4]. RNI to the axilla and SCF was given in 58 (15.1\%), 24 (7.6\%), and 15 (9.3\%) patients in START-pilot, START-A, and START-B trials, respectively. Dose fractionation used was different in all the trials. Patient population in these trials was also heterogeneous in term of extent of axillary dissection, RNI, radiation dose, technique and adjuvant systemic treatment. IMNI was not delivered in these trials. Finally these patients may not be representative of global population because of ethnicity and anthropometry variation. Patients included in START trials were $>50$ years of age and early stage. We have included young as well as elderly and advanced stage patients in the present study. The argument here might be slight lower PMRT dose of 35 Gy in our study as compared to 40 Gy in START trials, but our results in terms of local control [8-12] are comparable to START trials. This dose is also similar to UK IMPORT Low trial. However, the dose delivered to the axilla and SCF in the present study was same as in START B trial, i.e., $40 \mathrm{~Gy}$ in 15 fractions, the equivalent dose in $2 \mathrm{~Gy}\left(\mathrm{EQD}_{2 \mathrm{~Gy}}\right)$ of which is $46 \mathrm{~Gy}$ and $48 \mathrm{~Gy}$ assuming $\alpha / \beta$ values of $3 \mathrm{~Gy}$ and $1.5 \mathrm{~Gy}$, respectively.

In a recent well-designed randomised study by Wang et al. [6], they concluded that 3-week hypofractionation was non-inferior to conventional fractionation in terms of efficacy and safety. They reported similar clinical outcomes and toxicities between the two arms [6]. This study also established the safety of RNI in patients with breast cancer. They reported lymphedema rate of 19\% at 5 years which is comparable to $7 \%$ in the current study. Shoulder dysfunction of $8.8 \%$ in our study is slightly higher than that reported by Wang et al. [6] of 3\%. Our results in terms of lung and cardiac toxicities are also comparable to the hypofractionated arm of the study reported by Wang et al. [6]. They reported $<1 \%$ grade 3 lung and cardiac toxicities at 5 years in their study (Table 4).

In the present study, late cardiac and lung toxicities were minimal. RNI hardly contributes to the dose to the heart so there may not be any concern of late toxicity to this organ from RNI. Late cardiac toxicity in the present study even with RNI is comparable to the START data. Although more than half of our patients (56.5\%) had received anthracycline based chemotherapy, there was no excess cardiac toxicity. Hypofractionation studies from Belgium [14] and Thailand [15] on RNI and have not reported excess late cardiac toxicity. In our series of internal mammary node irradiation with hypofractionation with a median follow-up of 14 years there was

Table 2. Late toxicities $(n=1,770)$

\begin{tabular}{lccccc}
\hline \multirow{2}{*}{ Late toxicity } & \multirow{2}{*}{ Number of patients (\%) } & \multirow{2}{*}{$95 \% \mathrm{Cl}$} & \multicolumn{3}{c}{ Prevalence } \\
\cline { 5 - 6 } & & & At 5 years & At 10 years & At 15 years \\
\hline Arm/shoulder pain (moderate/marked) & $254(14.3)$ & $12.7-16.1$ & $141 / 1,254(11.3)$ & $74 / 856(8.6)$ & $37 / 418(9.2)$ \\
Shoulder stiffness (moderate/marked) & $219(12.3)$ & $10.9-14.0$ & $111 / 1,254(8.8)$ & $61 / 856(7)$ & $27 / 415(6.5)$ \\
Arm edema (moderate/marked) & $131(7.4)$ & $6.2-8.7$ & $95 / 1,353(7.0)$ & $62 / 854(7.2)$ & $30 / 420(7.1)$ \\
Cardiac (grade 3) & $29(1.6)$ & $1.1-2.3$ & $9 / 1,242(0.7)$ & $13 / 831(1.5)$ & $7 / 415(1.6)$ \\
Lung (grade 3) & $23(1.3)$ & $0.8-1.9$ & $9 / 1,231(0.7)$ & $9 / 827(1)$ & $5 / 412(1.2)$ \\
Rib fracture & $6(0.3)$ & $0.1-0.7$ & $2 / 1,254(0.1)$ & $2 / 854(0.2)$ & $2 / 418(0.5)$ \\
Second malignancy & $105(5.9)$ & $4.9-7.1$ & $19 / 1,245(1.5)$ & $39 / 837(4.6)$ & $42 / 420(10)$ \\
\hline
\end{tabular}

Values are presented as number (\%).

Table 3. Relationship between number of dissected nodes and arm edema $(n=1,770)$

\begin{tabular}{lclll}
\hline & Number of patients & Arm edema & $95 \% \mathrm{Cl}$ & $p$-value for trend \\
\hline $\begin{array}{l}\text { Number of dissected nodes } \\
\leq 10\end{array}$ & 843 & $41(4.9)$ & & $<0.001$ \\
$11-20$ & 752 & $68(9.0)$ & $7.5-6.5$ & \\
$>20$ & 175 & $22(12.6)$ & $8.0-11.3$ & \\
\hline
\end{tabular}

Values are presented as number (\%).

$\mathrm{Cl}$, confidence interval. 
no excess cardiac toxicity [9].

RNI does contribute dose to the lungs and may increase pulmonary toxicity but hypofractionated RNI has not been shown to increase its incidence as compared to standard fractionation [6]. With this dose fractionation pulmonary fibrosis rate was $1.3 \%$. This is consistent to the less than $2 \%$ in the published studies $[2,3,6]$. There was no grade 3 late pulmonary toxicity in the study by Wang et al. [6], but they reported grade 1-2 toxicity rate of 15\% (Table 4). This is also comparable to the EORTC study (1.3\%-4.3\%) [16]. Other studies on hypofractionated PMRT and RNI with limited patient numbers have also demonstrated reduced risk of pulmonary toxicity as compared to the standard fractionation $[14,15,17]$. In a study from Greece, intense asymptomatic radiographic findings of infield lung fibrosis were noted in 4 of 112 (3.6\%) patients with amifostine protection [17]. We could not find any association between the dosimetric factors and lung and heart toxicities in these patients, this may be because of dosimetry was done in small number of patients.

The rates of moderate/marked lymphedema of $7.4 \%$ in our study are also within the range reported in the literature (Table 4). Lateral border of supraclavicular field in the present study was deltoid insertion which means brachial plexus and shoulder joint were within the radiation field in these patients (Fig. 1B). Since this reported rate is with $2 \mathrm{D}$ technique, it would be likely less with modern 3D technique where deltoid and pectoral muscles, lateral SCF and shoulder joint are no more part of the RNI target volume. RNI field size following the ESTRO and RTOG guidelines are smaller than the conventional 2D fields thus sparing more normal tissue $[18,19]$. Our lymphedema rates are also comparable to the AMAROS study where it was $11 \%$ at 5 years [20]. RNI has been shown to increase arm lymphedema from 5\%-10\% after whole-breast irradiation (WBI) to 10\%-60\% with PMRT [20-27]. A Canadian study reported that lymphedema rate increased from $4.1 \%$ to $7.3 \%$ after WBI only [26]. In our study lymphedema rate significantly increased with the number of axillary lymph nodes dissected (Table 3). In START trials lymphedema rate ranged from $3.7 \%$ to $16.8 \%$ with hypofractionation as compared to $7.8 \%$ to $12.8 \%$ with conventional fractionation [4]. In the START trials, there were only 51-80 and 20-36 patients per arm at 5 and 10 years and number of events ranged from 0-5 and 0-2 at 5 and 10 years, respectively. Khan et al. [8] reported lymphedema in $4.5 \%$ patients at a median follow-up of 32 months. Wang et al. [6] reported grade 1-2 and grade 3 lymphedema rate of $20 \%$ and $1 \%$, respectively, in the hypofractionation arm. A study from Thailand also did not report any excess increase in the radiation-induced lymphedema as compared to conventional fractionation [15].

So far, we have not seen any brachial plexopathy with this dose fractionation. With conventional RT regimen the incidence of brachial plexopathy has been reported to be less than $5 \%$ and paraesthesia up to $20 \%$ [27]. If we consider $\alpha / \beta$ of 2 for brachial plexus, the BED delivered with this regimen would be 93 Gy compared to $100 \mathrm{~Gy}$ with standard fractionation. The dose fractionation schedule in the present study does not exceed tolerance of critical structures in the SCF and axilla. So there are likely less chances of de-

Table 4. Late toxicities with hypofractionation studies in breast cancer

\begin{tabular}{|c|c|c|c|c|c|c|c|c|c|}
\hline Study & Year & $\begin{array}{l}\text { Number of } \\
\text { participants }\end{array}$ & Population & Dose (Gy) & Fractions & Pulmonary & Cardiac & Arm edema & $\begin{array}{l}\text { Shoulder } \\
\text { dysfunction }\end{array}$ \\
\hline \multirow[t]{2}{*}{ START A trial [4] } & 2013 & 2,236 & Low risk & 39 & 13 & $1.2 \%$ & $1.5 \%$ & $6.5 \%$ & $10.5 \%$ \\
\hline & & $14 \% \mathrm{RNI}$ & & 41.6 & 13 & $1.1 \%$ & $1.1 \%$ & $16.8 \%$ & $8.7 \%$ \\
\hline \multirow[t]{2}{*}{ START B trial [4] } & 2013 & 2,215 & Low risk & 40 & 15 & $1.7 \%$ & $1.5 \%$ & $3.7 \%$ & $3.7 \%$ \\
\hline & & 7\% RNI & & & & & & & \\
\hline Whelan et al. [7] & 2010 & 1,234 & Low risk & 42.56 & 16 & NR & NR & $4.1 \%-7.3 \%$ & NR \\
\hline \multirow[t]{2}{*}{ Wang et al. [6] } & 2019 & 820 & High risk & 43.5 & 15 & G1-2: $15 \%$ & G3: $1 \%$ & G1-2: 19\% & $3 \%$ \\
\hline & & & & & & G3: $0 \%$ & & & \\
\hline $\begin{array}{l}\text { Pinitpatcharalert et al. } \\
\text { [15] }\end{array}$ & 2011 & 215 & High risk & $42.4-47.7$ & $16-18$ & All toxicities were simil & ar to conve & entional fraction & nation group \\
\hline \multirow[t]{2}{*}{ Koukourakis et al. [17] } & 2013 & 112 & High risk & 35 & 10 & $4 \%$ CT changes in lung & NR & G1-2: $11.6 \%$ & $1.8 \%$ \\
\hline & & $65 \% \mathrm{RNI}$ & & & & & & & \\
\hline \multirow[t]{2}{*}{ Van Parijs et al. [14] } & 2012 & 70 & Low risk & 42 & 15 & $\downarrow$ DLco $7 \%$ & $4.6 \%$ & NR & NR \\
\hline & & $33 \% \mathrm{RNI}$ & & & & & & & \\
\hline \multirow[t]{2}{*}{ Yarnold et al. [26] } & 2005 & 1,410 & Low risk & 39 & 13 & NR & NR & $8.3 \%$ & $18.1 \%$ \\
\hline & & $20 \% \mathrm{RNI}$ & & 42.9 & & & & $5.9 \%$ & $7.1 \%$ \\
\hline Present study & 2020 & 1,770 & High risk & $35 / 40$ & 15 & $1.6 \%$ & $1.6 \%$ & $7.4 \%$ & $12.3 \%$ \\
\hline
\end{tabular}

$\mathrm{RNI}$, regional nodal irradiation; $\mathrm{G}$, grade; NR, not reported; DLco, lung diffusion of carbon monoxide. 
veloping brachial plexopathy with this dose schedule. There was no brachial plexopathy in the study by Wang et al. [6]. In the START trials brachial plexopathy was reported in only one patient in START A trial [1]. However, there was no adverse effect on shoulder or arm function in START B trial [2]. Our RNI regimen is similar to START B regimen (40 Gy/15 fx/3 weeks) which is equivalent to 47 Gy in 2.0-Gy fractions if the $\alpha / \beta$ value for brachial plexus is $2.0 \mathrm{~Gy}$ or to $49 \mathrm{~Gy}$ in 2.0-Gy fractions, if $\alpha / \beta=1.0 \mathrm{~Gy}$ [28]. There are no data from a Royal Marsden study on RNI [29]. In a study from Greece where they treated 73/112 patients (65\%) with RNI, none had brachial plexopathy [17]. About $21 \%$ of patients in the present study received taxanes. Still, we did not observe an increase in arm paraesthesia and brachial plexopathy with this RT schedule. In our past series of PMRT and RNI also we have not observed excess risk of arm edema or brachial plexopathy [8-12].

Of all second malignancies majority 61 (58\%) were in the opposite breast. Out of 44 non-breast second malignancies 6 (5.7\%) were associated with RT. Breast and non-breast second malignancy risk associations have been discussed in detail and published previously from our department [30-32].

World's 85\% population lives in low-middle income countries [33]. As breast cancer is a leading cancer in females and RT is an important part of its locoregional management, hypofractionation will reduce the waiting time for radiation in the limited resource countries. Hypofractionation also reduces treatment time to half with similar control rates and lesser late toxicities compared to conventional fractionation with economic gain. In low-in-come countries with limited resources where 3D treatment is not possible, $2 \mathrm{D}$ treatment with modification of the RT fields as per ESTRO and RTOG guidelines may be possible.

Limitations of the study are its retrospective nature, single institutional and inclusion of limited patients who received IMNI. The minimal cardiac toxicity of this study should be interpreted with caution in this context. Although all the patients were treated with simple 2D RT technique but dose delivered was similar to standard hypofractionation which is likely to be future of PMRT and RNI. Since majority of patients with breast cancer in the developed world at present are treated with modern techniques like 3D conformal RT or intensity-modulated RT, likely risk of late toxicities in these patients would be less. The current study may not reflect the late toxicity that we have with current RT techniques. But in the limited resource countries majority of breast cancer patients are still treated with 2D technique as it is simple to plan and execute. Field sizes used always depend on the anthropometry of the patient, so it is also an individualised treatment. For breast cancer postoperative RT, 2D or 3D techniques may not make a difference if the dose used is within this hypofractionation schedule with proper planning and field alignment. Postoperative pre-RT toxicity is not reported here. Patient reported outcomes will be part of a separate study. Very few patients in the study received trastuzumab because of economic reasons so its impact on outcomes and late cardiac toxicity cannot be evaluated. None of our patients had undergone breast reconstruction so it would be difficult to comment on rates of complications in these patients. Last two situations are common in the limited resource countries.

Strengths of the study are large numbers of patients with longterm, regular follow-up; patients with stage II and III breast cancer treated with hypofractionated RT to the chest wall and RNI including IMNI with same dose fractionation in all the patients, young as well as elderly patients with simple conventional 2D planning which is possible in any centre in any limited resource country with economic implications. The study may also add to the experience of hypofractionated RT with systemic treatment with anthracyclines and taxanes which raises concern of cardiac and pulmonary toxicity, paraesthesia, brachial plexopathy and lymphedema, respectively. From our experience, hypofractionated RT with anthracyclines and taxanes seems to be safe. The American Society for Radiation Oncology (ASTRO) has also realised that hypofractionation may be more acceptable to patients because of its convenience and economic benefit. They suggested that in women aged $\geq 50$ years with early breast cancer, WBI should not be started without giving option of hypofractionation [34]. Recently ASTRO widened these recommendations to any age and stage [35]. However, such advisory for PMRT and RNI with shorter fractionations are lacking. Although retrospective, reporting these outcomes may strengthen data on hypofractionated PMRT and RNI. It may also encourage utilization of RT in limited resource countries where breast cancer patients travel long distance for treatment. It has its economic implications for the patient, family and for the country as a whole.

In conclusion, in women with breast cancer, after mastectomy $40 \mathrm{~Gy} / 15 \mathrm{fx} / 3$ weeks hypofractionated RNI with 2D technique seems to be safe and comparable to historical data of conventional fractionation.

\section{Conflict of Interest}

No potential conflict of interest relevant to this article was reported.

\section{References}

1. von Minckwitz G, Untch M, Blohmer JU, et al. Definition and impact of pathologic complete response on prognosis after neoad- 
juvant chemotherapy in various intrinsic breast cancer subtypes. J Clin Oncol 2012;30:1796-804.

2. START Trialists' Group. The UK Standardisation of Breast Radiotherapy (START) Trial A of radiotherapy hypofractionation for treatment of early breast cancer: a randomised trial. Lancet Oncol 2008;9:331-41.

3. START Trialists' Group. The UK Standardisation of Breast Radiotherapy (START) Trial B of radiotherapy hypofractionation for treatment of early breast cancer: a randomised trial. Lancet 2008;371:1098-107.

4. Haviland JS, Owen JR, Dewar JA, et al. The UK Standardisation of Breast Radiotherapy (START) trials of radiotherapy hypofractionation for treatment of early breast cancer: 10-year follow-up results of two randomised controlled trials. Lancet Oncol 2013;14:1086-94.

5. Early Breast Cancer Trialists' Collaborative Group. Favourable and unfavourable effects on long-term survival of radiotherapy for early breast cancer: an overview of the randomised trials. Lancet 2000;355:1757-70.

6. Wang SL, Fang H, Song YW, et al. Hypofractionated versus conventional fractionated postmastectomy radiotherapy for patients with high-risk breast cancer: a randomised, non-inferiority, open-label, phase 3 trial. Lancet Oncol 2019;20:352-60.

7. Whelan TJ, Pignol JP, Levine MN, et al. Long-term results of hypofractionated radiation therapy for breast cancer. N Engl J Med 2010;362:513-20.

8. Khan AJ, Poppe MM, Goyal S, et al. Hypofractionated postmastectomy radiation therapy is safe and effective: first results from a prospective phase II trial. J Clin Oncol 2017;35:2037-43.

9. Yadav BS, Sharma SC, Ghoshal S, Kapoor RK, Kumar N. Postmastectomy internal mammary node radiation in women with breast cancer: a long-term follow-up study. J Radiother Pract 2015; 14:385-93.

10. Yadav BS, Sharma SC, Singh $R$, Singh G. Patterns of relapse in locally advanced breast cancer treated with neoadjuvant chemotherapy followed by surgery and radiotherapy. J Cancer Res Ther 2007;3:75-80.

11. Yadav BS, Sharma SC, Singh R, Singh G, Kumar V. Postmastectomy radiation and survival in patients with breast cancer. J Cancer Res Ther 2007;3:218-24.

12. Yadav BS, Sharma SC, Patel FD, Bose SM, Ghoshal S, Kapoor RK. Therapeutic benefit of radiotherapy after surgery in patients with T1-T2 breast tumour. J Radiother Pract 2010;9:33-40.

13. Yadav BS, Sharma SC, George P, Bansal A. Post-mastectomy radiation beyond chest wall in patients with $\mathrm{N} 1$ breast cancer: is there a benefit? J Cancer Res Ther 2014;10:279-83.

14. Van Parijs H, Miedema G, Vinh-Hung V, et al. Short course radio- therapy with simultaneous integrated boost for stage I-II breast cancer, early toxicities of a randomized clinical trial. Radiat Oncol 2012;7:80.

15. Pinitpatcharalert A, Chitapanarux I, Euathrongchit J, Tharavichitkul E, Sukthomya V, Lorvidhaya V. A retrospective study comparing hypofractionated radiotherapy and conventional radiotherapy in postmastectomy breast cancer. J Med Assoc Thai 2011;94 Suppl 2:S94-102.

16. Poortmans P, Kouloulias V, van Tienhoven G, et al. Quality assurance in the EORTC randomized trial 22922/10925 investigating the role of irradiation of the internal mammary and medial supraclavicular lymph node chain works. Strahlenther Onkol 2006;182:576-82.

17. Koukourakis MI, Panteliadou M, Abatzoglou IM, Sismanidou K, Sivridis E, Giatromanolaki A. Postmastectomy hypofractionated and accelerated radiation therapy with (and without) subcutaneous amifostine cytoprotection. Int J Radiat Oncol Biol Phys 2013;85:e7-13.

18. Offersen BV, Boersma $\sqcup$, Kirkove $C$, et al. ESTRO consensus guideline on target volume delineation for elective radiation therapy of early stage breast cancer. Radiother Oncol 2015;114:3-10.

19. Radiation Therapy Oncology Group. Breast cancer atlas for radiation therapy planning: consensus definitions [Internet]. Philadelphia, PA: Radiation Therapy Oncology Group; 2016 [cited 2020 May 10]. Available from: https://www.rtog.org/CoreLab/ContouringAtlases/BreastCancerAtlas.aspx.

20. Donker M, Slaets L, van Tienhoven G, Rutgers EJ. Axillary lymph node dissection versus axillary radiotherapy in patients with a positive sentinel node: the AMAROS trial. Ned Tijdschr Geneeskd 2015;159:A9302.

21. Shah $C$, Wilkinson JB, Baschnagel $A$, et al. Factors associated with the development of breast cancer-related lymphedema after whole-breast irradiation. Int J Radiat Oncol Biol Phys 2012; 83:1095-100.

22. Ugur S, Arici C, Yaprak M, et al. Risk factors of breast cancer-related lymphedema. Lymphat Res Biol 2013;11:72-5.

23. Jung SY, Shin KH, Kim M, et al. Treatment factors affecting breast cancer-related lymphedema after systemic chemotherapy and radiotherapy in stage $\mathrm{I} / \mathrm{III}$ breast cancer patients. Breast Cancer Res Treat 2014;148:91-8.

24. Chandra RA, Miller CL, Skolny MN, et al. Radiation therapy risk factors for development of lymphedema in patients treated with regional lymph node irradiation for breast cancer. Int J Radiat Oncol Biol Phys 2015;91:760-4.

25. Yarnold J, Bentzen SM, Coles C, Haviland J. Hypofractionated whole-breast radiotherapy for women with early breast cancer: myths and realities. Int J Radiat Oncol Biol Phys 2011;79:1-9. 
26. Whelan TJ, Olivotto I, Ackerman I, et al. NCIC-CTG MA. 20: an intergroup trial of regional nodal irradiation in early breast cancer. J Clin Oncol 2011;29(18_suppl):LBA1003.

27. Badiyan SN, Shah C, Arthur D, et al. Hypofractionated regional nodal irradiation for breast cancer: examining the data and potential for future studies. Radiother Oncol 2014;110:39-44.

28. Yarnold J, Ashton A, Bliss J, et al. Fractionation sensitivity and dose response of late adverse effects in the breast after radiotherapy for early breast cancer: long-term results of a randomised trial. Radiother Oncol 2005;75:9-17.

29. Owen JR, Ashton A, Bliss JM, et al. Effect of radiotherapy fraction size on tumour control in patients with early-stage breast cancer after local tumour excision: long-term results of a randomised trial. Lancet Oncol 2006;7:467-71.

30. Yadav BS, Sharma SC, Patel FD, Ghoshal S, Kapoor RK. Second primary in the contralateral breast after treatment of breast cancer. Radiother Oncol 2008;86:171-6.
31. Yadav BS, Sharma SC, Patel FD, Ghoshal S, Kapoor R, Kumar R. Nonbreast second malignancies after treatment of primary breast cancer. Int J Radiat Oncol Biol Phys 2009;73:1489-92.

32. Yadav BS, Sharma SC, Patel FD, Rai B, Ghoshal S. Gynecological Cancer as a Second Malignancy in Patients With Breast Cancer. Int J Gynecol Cancer 2017;27:1298-304.

33. International Atomic Energy Agency. Planning national radiotherapy services: a practical tool. Vienna, Austria: International Atomic Energy Agency; 2010.

34. Hahn C, Kavanagh B, Bhatnagar A, et al. Choosing wisely: the American Society for Radiation Oncology's top 5 list. Pract Radiat Oncol 2014;4:349-55.

35. Smith BD, Bellon JR, Blitzblau R, et al. Radiation therapy for the whole breast: Executive summary of an American Society for Radiation Oncology (ASTRO) evidence-based guideline. Pract Radiat Oncol 2018;8:145-52. 